\title{
Interdependent Concepts and their Independent Uses: Mental Imagery and Hallucinations
}

\author{
Eden T. Smith
}

University of Melbourne

\begin{abstract}
The scientific concepts of mental imagery and ballucinations are each used independently of the other in experiments; uses that simultaneously evoke and obscure their historical connections. To bighlight one of these connections, I will begin by sketching episodes from the largely separate developmental trajectories of each concept. Considering these historical sketches side-by-side, I will argue that the independent uses of these concepts each inherited a shared set of interdependent associations. In doing so, I seek to illustrate the value of examining historical connections between mental imagery and ballucinations for studying the current uses of these two concepts in neuroimaging experiments.
\end{abstract}

\section{Introduction}

The scientific concepts of mental imagery and hallucinations are each used independently of the other; uses that simultaneously evoke and obscure their historical connections. In this paper, I aim to illustrate the relevance of examining one of these historical connections for studying the current uses of these two concepts in neuroimaging experiments. To this end, I will highlight interdependent associations within the histories of each of the concepts that continue to contribute to their independent uses.

That mental imagery and hallucinations are used independently of each other is evident in the way that each concept influences investigations in isolation of the other. Within the neurosciences, mental imagery is treated as inconsequential to investigations using the concept of hallucinations, and vice-versa. For example, in the special Research Topics issue on mental imagery that Joel Pearson and Stephen Kosslyn (2013) edited for Frontiers in Human Neuroscience, hallucinations are only mentioned in one of the sixteen articles collected. There was a corresponding lack of interest in mental imagery within the edited publication The Neuroscience of Hallucinations; 
when mentioned at all, imagery was either dismissed as irrelevant to research into the cause of hallucinations (Aleman and Vercammen 2013), or merely provided one of the control conditions to which hallucinations can be compared (Dollfus, Alary, and Razafimandimby 2013; Ford and Hoffman 2013).

Although obscured by these independent uses, the definitions of mental imagery and hallucinations share a core element: a type of mental phenomena where sensations occur in the absence of relevant sensory stimuli (Roeckelein 2004; Aleman and Larøi 2008). In both cases, these mental phenomena are felt, to varying degrees, "as if" one or more sensory system has been stimulated in the absence of the relevant perceptual stimulidescribed as being "heard," "seen," "tasted," "felt" and so forth (Landis and Mettler 1964; Casey 2000). Given this, mental imagery and hallucinations can both be regarded as concepts used to investigate types of sensory-like mental phenomena-or, hereafter, SLMP. ${ }^{1}$

Differentiating between these types of SLMP tends to boil down to a difference of degree: while mental imagery resembles sensory perception, hallucinations involve a compelling sense of perception. As a broader analytic category, SLMP draws attention to the work that went into differentiating between those types of SLMP that have a compelling sense of perception (hallucinations) and those SLMP that merely resemble perception (mental imagery). In examining this distinction, I identified historical connections between the concepts that remain relevant and how the current uses of these concepts contribute to neuroimaging experiments.

To highlight one such connection, I will sketch episodes from the developmental trajectories of each concept. ${ }^{2}$ Then, by considering these largely separate trajectories side-by-side I will outline a series of interdependent associations inherited from an old philosophical view that SLMP mediate between perception and abstract thought. As I will argue, interdependent associations inherited from this mediator-view of SLMP remain entrenched within independent uses of the concepts of mental imagery and hallucinations. To this end, I will begin by clarifying my historiographical approach and positioning my research within historical and philosophical explorations into how the uses of concepts contribute to scientific practice.

In the second section, I will sketch an account of how the concept of mental imagery came to be used for investigating the neurocognitive

1. The term sensory-like mental phenomena (SLMP) is similar to "phantom perceptions" (J. Pearson and Westbrook 2015), yet is intended to encompasses all sensory modalities and carry less clinical connotations.

2. For the sake of clarity, I will limit this discussion to the uses of the concepts of mental imagery and hallucinations for investigating wakeful and endogenous SLMP. 
functions of ordinary SLMP. This will involve drawing on historical accounts of the developing concept of mental imagery (Holt 1964; Bower 1984; Denis, Engelkamp, and Richardson 1988; Denis 2012; MacKisack et al. 2016). To supplement these, I will consider scientific texts published during the nineteenth and twentieth centuries. Within the many layers of historical context, I will focus on outlining how the current concept of mental imagery stabilized through the articulation of characteristics considered causally fundamental for individuating instances of ordinary SLMP when investigating functional neurocognition.

In the third section, I will outline the debated uses of the concept of hallucinations for investigating the roles of SLMP in neurocognitive dysfunction. The dynamics of these debates intersect with other heavily contested concepts-including psychopathology, self-regulation, and schizophrenia. ${ }^{3}$ Drawing on historical accounts of these intersections, I will focus on a specific thread within the development of the concept of hallucinations. ${ }^{4}$ This thread centers on how the current concept of hallucinations stabilized through the articulation of characteristics considered causally fundamental for individuating pathological SLMP when investigating dysfunctional neurocognition.

Drawing the first three sections together, the fourth will compare the characterizations of specific types of SLMP within the developmental trajectories of both mental imagery and hallucinations. Building on this analysis, I will highlight how both concepts share a set of entrenched associations. In doing so, I will argue that these associations were carried along by characteristics that integrated nineteenth century knowledge about SLMP in ways that helped stabilize the uses of each concept as independent of the other. In brief, the uses of these two concepts preserve the subterranean associations that distinguish between ordinary and pathological forms of SLMP by measuring or explaining the degree that sensations are regulated by abstract thought (see Table 1). These structured associations helped the concepts of mental imagery and hallucinations to stabilize despite the difficulty of distinguishing the SLMP of interest from other types of SLMP (see Table 2 and Table 3). Individuated in this way, each concept came to be used independently of the other for investigating functional and dysfunctional neurocognitive processes respectively.

3. For more on these other concepts, see: Rabkin 1970; Scull 1983; Pilgrim 2007; Berrios 2013; 2014.

4. Note that philosophical and historical views on psychiatric concepts vary. I draw on historiographical approaches emphasising the dynamic contingencies in conceptual development. See Kenneth Schaffner and Kathryn Tabb (2014) for a discussion of the range of philosophical approaches to the construction of psychiatric concepts. 
Table 1. Inverse Characteristics of Mental Imagery and Hallucinations

\begin{tabular}{|c|c|c|c|}
\hline Characteristic & $\begin{array}{l}\text { Mental } \\
\text { Imagery }\end{array}$ & Hallucinations & $\begin{array}{l}\text { Mediator Views } \\
\text { of Characteristic }\end{array}$ \\
\hline $\begin{array}{l}\text { Reported } \\
\text { Location }\end{array}$ & Internal & External & \multirow{3}{*}{$\begin{array}{l}\text { Explains why SLMP are (or are not) } \\
\text { able to be judged as distinct from } \\
\text { perception }\end{array}$} \\
\hline $\begin{array}{l}\text { Perceptual } \\
\text { Similarity }\end{array}$ & $\begin{array}{l}\text { Vivid } \\
\text { Fleeting }\end{array}$ & $\begin{array}{l}\text { Abnormally Vivid } \\
\text { Concrete }\end{array}$ & \\
\hline $\begin{array}{l}\text { Volition and } \\
\text { Control }\end{array}$ & $\begin{array}{l}\text { Manipulable } \\
\text { Dismissible }\end{array}$ & $\begin{array}{l}\text { Obstinate } \\
\text { Absorbing }\end{array}$ & \\
\hline Attribution & Self & Other & \multirow{2}{*}{$\begin{array}{l}\text { Measures degree that SLMP are } \\
\text { regulated by reason }\end{array}$} \\
\hline Insight & Maintained & Lacking & \\
\hline
\end{tabular}

\section{Examining the Uses of Scientific Concepts}

Treating both mental imagery and hallucinations as conceptualizing different experiences of SLMP provides an avenue for examining how each came to be used in current experimental practices. In many ways, this approach follows the tradition of examining present conceptual practices through reconstructing histories of how a concept emerged (Tiles 1984; Hacking 2002; Schickore 2002; Rheinberger 2010). However, in contrast to the many detailed historical accounts in this tradition, my intention is simply to highlight one connection between the largely separate

Table 2. Comparing Historical Characterisations for Types of SLMP

\begin{tabular}{|c|c|c|c|c|}
\hline Characteristic & $\begin{array}{l}\text { Mental } \\
\text { Imagery }\end{array}$ & $\begin{array}{l}\text { Eidetic } \\
\text { Imagery }\end{array}$ & $\begin{array}{l}\text { Pseudo- } \\
\text { hallucination }\end{array}$ & Hallucinations \\
\hline $\begin{array}{l}\text { Reported } \\
\text { Location }\end{array}$ & Internal & External & $\begin{array}{l}\text { Internal } \\
\text { OR } \\
\text { External }\end{array}$ & External \\
\hline $\begin{array}{l}\text { Perceptual } \\
\text { Similarity }\end{array}$ & $\begin{array}{l}\text { Fleeting } \\
\text { Vivid }\end{array}$ & $\begin{array}{l}\text { Concrete } \\
\text { Abnormally Vivid }\end{array}$ & & \\
\hline $\begin{array}{l}\text { Volition and } \\
\text { Control }\end{array}$ & $\begin{array}{l}\text { Manipulable } \\
\text { Dismissible }\end{array}$ & & $\begin{array}{l}\text { Obstinate } \\
\text { Absorbing }\end{array}$ & \\
\hline Attribution & Self & & $\begin{array}{l}\text { Self } \\
\text { OR } \\
\text { Other }\end{array}$ & Other \\
\hline Insight & Maintained & & & Lacking \\
\hline
\end{tabular}


Table 3. Comparing Current Characterisations for Types of SLMP

\begin{tabular}{lllll}
\hline Characteristic & $\begin{array}{l}\text { Mental } \\
\text { Imagery }\end{array}$ & $\begin{array}{l}\text { Intrusive } \\
\text { Imagery }\end{array}$ & $\begin{array}{l}\text { Non-pathological } \\
\text { hallucination }\end{array}$ & Hallucinations \\
\hline $\begin{array}{l}\text { Reported } \\
\text { Location }\end{array}$ & Internal & & $\begin{array}{l}\text { Internal } \\
\text { OR } \\
\text { External }\end{array}$ & External \\
$\begin{array}{l}\text { Perceptual } \\
\text { Similarity }\end{array}$ & Fleeting & Vivid & $\begin{array}{l}\text { Concrete } \\
\text { Abnormally Vivid }\end{array}$ & \\
$\begin{array}{l}\text { Volition and } \\
\text { Control }\end{array}$ & Manipulable & $\begin{array}{l}\text { Obstinate } \\
\text { Absorbing }\end{array}$ & & \\
Attribution & Self & & Self & Other \\
& & & OR & Other \\
Insight & Maintained & & & Lacking \\
\hline
\end{tabular}

developmental trajectories of each concept. Given this, my historiographical approach is narrow; I will leave aside the tapestry of sociological and technological contexts required for understanding the broader historical developments that gave rise to these two concepts. Instead, I will focus on highlighting a connection between how the scientific concepts of mental imagery and hallucinations each came to be used as stable scientific concepts for investigating the neurocognitive procesess of SLMP. ${ }^{5}$

This focus is motivated by historical and philosophical studies that examine how the uses of scientific concepts enable scientific practices (e.g., Feest 2010; Boon 2012; Steinle 2012). Examining concepts "as used" extends beyond analyses of concepts as mere mental or linguistic representations (MacLeod 2012; Nersessian 2012). These approaches help to sidestep the ongoing debates over concept meaning and reference (Feest and Steinle 2012). For example, Uljana Feest (2010) proposes that scientific concepts can be thought of as tools because, like material instruments, they enable the generation of experimental data. In relation to this, Feest (2010) describes two specific data generating functions that concepts can play: identifying whether a given type of phenomena is present in a given

5. This focused historical account is partial; integration with insights from other approaches is required to understand the broader dynamics of these practices (see Camilleri 2015). For example, experimental uses of each concept could be considered in relation to the societal reasoning-style scope of "organizing concepts" such as pathology (Hacking 2002; Sciortino 2016). 
condition; and intervening in the domain of study. Both functions rely on the ability of the tool (concept) to successfully individuate the type of phenomena of interest by delineating the class of phenomenon of interest from other types of phenomena within an available body of knowledge (Feest 2010). To function in these ways, a concept definition must adhere to a range of epistemic requirements while also condensing and integrating the available scientific knowledge of the time (Bloch 2012a). ${ }^{6}$ For example, causally fundamental explanations for a phenomenon can become associated with its typical characteristics; condensing the available knowledge and satisfying the epistemic requirement of differentiating the phenomena of interest from others (Bloch 2012a).

Examining their uses as tools highlights that concept definitions are able to pick out instances of a phenomena even when the causal nature of the kind of phenomena being investigated is unknown (Bloch 2012a). The stability of these tools can be understood by recognizing that concepts can only by judged as appropriate, or not, in relation to their use for a given purpose (Steinle 2010). In relation to this, it is important to recognize that the current stable uses of scientific concepts can often be tied to specific historically contingent goals (Brigandt 2010, 2012; Steinle 2012). To repurpose Gaston Bachelard's argument, it is only by examining the route which led to the dynamic and "public life" of current concepts that the historical accretions entrenched in these terms (and carried along by their uses) can be realized (Tiles 1984, pp. 157-59).

Therefore, before examining the current uses of the concepts of mental imagery and hallucinations as tools in neuroimaging experiments, preliminary questions need to be asked. In this paper, I focus on one question: what knowledge was integrated by these two concepts as each stabilized for use as independent experimental tools? In answering this question, I will sketch episodes from the developmental trajectories of the scientific concepts of mental imagery and hallucinations respectively. With these in place, I will then examine the shared associations that weave through the developmental trajectories of both concepts.

\section{Mental Imagery and the Investigation of Neurocognitive Function}

Within the neurosciences, mental imagery is used as a concept for investigating ordinary internal experiences that resemble sensory perception in the absence of the relevant sensory stimuli (Roeckelein 2004; Wang et al. 2010; Waller et al. 2012). As an example of how imagery resembles perception, Edward Titchener famously described recalling a lecture by

6. Bloch's approach builds on Feest's (2010) account of operational definitions, which is explicitly different from accounts in philosophical discussions around concept meaning. 
"seeing" a written table of contents visible in his mind's eye and "hearing" his own voice "speaking just ahead" of him (Titchener 1909, p. 8).

If this type of phenomena is unfamiliar, consider what sensations you experience when imagining your favorite beach. For some, imagining beaches requires recreating associated sensations: perhaps "hearing" waves crashing, "seeing" the blue-green water, or "feeling" hot sand squishing underfoot. Others can imagine that their favourite beach has blue-green water and hot sand-without experiencing any SLMP to do so. These and other individual differences in the degree of similarity between a given experience of thinking about a sensation (recalling or imagining being at a beach) and the actual perceptual sensation (of being at the beach) have been repeatedly documented (Betts 1909; Faw 2009; Hubbard 2013).

This heterogeneity in individual mental representations of sensory data are frequently overlooked (J. Pearson and Kosslyn 2015). Instead, the range of mental imagery "abilities" are typically taken as conforming to a Gaussian distribution (Roeckelein 2004). The tail-ends of this distribution are usually ignored. Taken as the most ordinary experience, recalling, imagining, and anticipating sensory based experiences (e.g., visiting a beach) are often portrayed as requiring mental imagery (e.g., Denis, Mellet, and Kosslyn 2004). ${ }^{7}$

In line with this, the concept of mental imagery is routinely used to investigate the reproduction of past sensory perception in memory, and the combination, modification, and construction of sensory like information in novel ways during imagination (e.g., Stephen M. Kosslyn, Ganis, and Thompson 2010; Andrade et al. 2014). In this research, experimental tasks of memory or imaginations are frequently assumed to require mental imagery (e.g., Halpern et al. 2004; Bien and Sack 2014).

This view of mental imagery as essential to memory and imagination is often traced back to an empiricist philosophical view of sense images as mediating between perception and abstract thought. ${ }^{8}$ Briefly, this mediatorview of SLMP emerges from a philosophical tradition that positions sense images as a necessary and mundane element in the process of recalling or anticipating perceptual information. Importantly, the reliability of this mediating capability was frequently qualified as depending on sense images being active and voluntary or, if passive, able to be controlled by rational judgement (Cocking 1991, pp. 24-5). An example of this classic mediator view can be seen in David Hume's description of the unification of simple

7. For exceptions, see: Reisberg, Pearson, and Kosslyn 2003; Logie et al. 2011; MacKisack et al. 2016; J. Pearson 2014.

8. This view sits within a broader philosophical tradition that regards all bodily experiences as subservient to abstract knowledge, see: Cocking 1991. 
sensory based ideas into complex ideas (Hume [1739] 2003). As part of this, Hume ([1739] 2003, pt. 1.3, 1.4, 1.7) described memory as the assessment and preservation of vivid copies of sensory impressions; and imagination as malleable sensory impressions that could be re-assembled to serve the more complex processes of abstract thought, if guided by a gentle dominating force.

The mediator views of SLMP that Hume's account of memory and imagination contributes to is just one side of a much older, and ongoing, philosophical debate over whether imagery is critical to ordinary thinking processes or an inconsequential curiosity (MacKisack et al. 2016). Both sides of these debates have been criticized for relying on the same unjustified philosophical assumption: "that one's own mental 'intuition' is representative of homo sapiens mentalis" (Faw 2009, pp. 7-8; original emphasis). Nonetheless, longer-running debates aside, it was classic mediator views that dominated philosophical approach to memory and imagination during the nineteenth century (Cocking 1991). These philosophical accounts were influential on nineteenth century uses of mental imagery in scientific investigations (Bower 1984; Cocking 1991).

Viewed as essential to mediating between perception and thought, mental imagery began to be investigated through the introspective techniques common to psychological investigations in the late nineteenth century (Holt 1964; Paivio 1970; Brann 1991). In one famous example, Francis Galton (1883) asked subjects to recall seeing their breakfast table and, reporting a wide range responses, concluded that mental imagery was a common faculty that played an important role in memory, if subordinate to abstract thought. Although not the first, Galton's imagery questionnaire was influential in the trend towards quantifying types of imagery experiences within experimental psychology (MacKisack et al. 2016). To this end, Galton's questionnaire was later developed for use in further studies (Angell 1910; Holt 1964). In these studies, the reported characteristics of an image based memory - such as degree of vividness, persistency, and controllabilitywere then compared across subjects and statistically analyzed (e.g., Armstrong 1894; French 1902). Despite documenting individual variability, investigations centered on those images thought to best serve abstract thought. In line with mediator views of SLMP, memory relied on a clear resemblance to perception (imagery as vivid) that nonetheless remained appropriately regulated by reason (imagery as manipulable and dismissible).

By the early twentieth century the classic mediating role of SLMP had been subtly modified. No longer required for thought, SLMP were repositioned as a stage of intellectual development that should be subordinate to abstract thought by adulthood. For example, George H. Betts (1909) emphasised individual variability of imagery experiences while simultaneously 
dismissing reliance on imagery as childlike. Rather than simple image based ideas combining to form complex abstract ideas, children relied on simple imagery yet grew up into adults with complex abstract thoughts.

In line with this modification, the classic mediating position of SLMP was explicitly rejected within the imageless-thought debates of the early twentieth century. Two brief examples from this debate illustrate the polarized views of these debates. First, in an example defense of classical mediator views of SLMP, James Angell argued that experiments suggesting that memory and movement rely on "sensational or imaginal factors" demonstrated that the imageless-thought doctrine remained "open to suspicion" (Angell 1911, pp. 322-23). Secondly, challenges to this mediator view of imagery are exemplified by R.S. Woodworth's comment that "all recall is of facts previously noted, freed from the concrete setting in which they occurred when noted" (Woodworth 1915, p. 15).

Both sides of this debate shared the long held philosophical assumption mentioned earlier: that personal experiences of thinking are representative of well-reasoned thinking in general. For example, both Angell and Woodworth drew upon their own introspective experiences while dismissing the validity of the introspection of their opponents. For example, Angell entertained the possibility of radically different types of mental organization, only to reject this as less likely than the probability that proponents of imageless-thinking were merely ineffective at introspection (Angell 1911). In a similarly obstinate approach, Woodworth detailed his own imageless analytic reasoning in support of his argument that accounts of vivid imagery should be dismissed as merely a "revival of personal attitude and emotional value" (Woodworth 1915, pp. 14-22).

Reflecting the increasing dominance of the imageless-thought position, studies using the concept of mental imagery began to emphasise that ordinary SLMP are an optional addition to abstract thought. For example, investigations using the concept of mental imagery during the early twentieth century repeatedly described imaging abilities as decreasing with age, or as replaced by improved skills in abstract thinking (e.g., Alexander 1904; Kuhlmann 1906; Langfeld 1916). In some cases, these arguments were extended to openly dismiss mental imagery as an impractical and emotional reaction (e.g., Kuhlmann 1906; Langfeld 1916).

A striking illustration of this shift is evident in the attempts to account for eidetic images - a phenomenon characterized by the projection into perceptual space of vivid sensory based memories (Allport 1924; Edgell 1936; Blom 2010). Multiple conflicting proposals for the relationship between eidetic images and other SLMP were presented. Most commonly considered a unique type of SLMP, eidetic imagery was also proposed to 
be a form of SLMP that differed from ordinary imagery simply by degree (Gray and Gummerman 1975). In both proposals, the high degree of perceptual similarity was explained as useful during the developmental stages of childhood; eventually being replaced by abstract thought in normal adults (e.g., Allport 1924). However, given the high degree of vividness and external location, other characteristics were required to distinguish these childhood SLMP from hallucinations; notably, insight (Brann 1991) and degree of volitional control (Faw 2009).

By the late 1930s imageless-thinking proponents had prevailed; it became common to emphasize that mental imagery should be replaced by the imageless abstract thoughts of adulthood (e.g., Dumville 1931; Edgell 1936). With mental imagery dismissed as childish, the mediator role that imagery previously held between perception and abstract thought was abandoned; replaced by verbal or behavioral responses (Paivio 1969). Consequently, almost three decades passed with scientific investigations rarely using the concept of mental imagery for investigating cognitive function (Holt 1964; Hebb 1968; S. M. Kosslyn, Behrmann, and Jeannerod 1995). ${ }^{9}$ Those few studies that did investigate mental imagery between the 1930s and 1960s focused on describing "objectively measurable" behaviors, such as measuring respiration rhythms during imagery in different senses (e.g., Schilder 1933; Golla, Hutton, and Walter 1943).

As mentioned earlier, typical characteristics of a concept can help to stabilize the uses of that concept for individuating instances of a specific type of phenomena for further investigation. ${ }^{10}$ To do this, the type of phenomena of interest needs to be differentiated from potentially similar types of phenomena. This practice can be seen in the few studies using the concept of mental imagery during this time explicitly distancing their investigation of ordinary SLMP from the higher-profile concept of hallucinations. For example, in a report on the relationship between respiration rates and imagery modalities, P. L. Short described mental imagery as sensory experiences that differ from hallucinations by being more easily controlled (Short 1953).

These fallow period studies provided important groundwork for later research by offering compelling demonstrations that imagery experiences could influence behavior. No longer a mere epiphenomenal curiosity, mental imagery returned as a legitimate concept for use in scientific

9. Although accounting for this fallow period is beyond scope, it is worth noting the range of interconnected factors implicated: the rejection of introspective techniques as subjective; behaviorism in psychology; the "turn to language" within analytic philosophy; and increased skepticism of quasi-perceptual experiences in philosophical phenomenology, (see Holt 1964; Kind 2001; J. Pearson 2014).

10. As earlier, see Feest 2010; Bloch 2012a. 
investigations (Cooper 1995). ${ }^{11}$ Even so, it wasn't until the 1960s that researchers returned to testing what function mental imagery plays in neurocognition (Holt 1964; Paivio 1969). In contrast to the nineteenth century questionnaires, individual variance in experimental psychology was regarded as an "error variance" that should be reduced by any means possible (Cronbach 1957, p. 674). As such, legitimacy for the concept of mental imagery required careful characterization: the SLMP of interest were ordinary volitional experiences shared with minimal variation by all healthy individuals. As part of this, uses of the concept of imagery continued to be defended by emphasizing how ordinary SLMP differed from the undesirable characteristics associated with those SLMP conceptualized as hallucinations (e.g., Reed 1972).

Supported by these subterranean characterizations of ordinary SLMP as an important element of thought, the concept of mental imagery stabilized for use in investigating neurocognitive function. For example, experiments into how imagery-strategies might improve memory began using the concept of mental imagery without describing the characteristics of these SLMP, relying on familiarity with the concept for investigating neurocognitive function (e.g., Anderson and Kulhavy 1972; Pressley 1976). Indeed, during the 1970s the concept of mental imagery was routinely used across multiple distinct research projects: including research into perception, learning, motor control, language comprehension, and abstract reasoning (Intons-Peterson 1992; Kosslyn et al. 1995).

During the 1980s, a new imagery debate emerged that focused almost exclusively on visual imagery (Intons-Peterson 1992). One side maintained the view that visual imagery resembles perceptual information by preserving both pictorial and spatial properties of visual stimuli; the other side proposed that visual "images" are simply language like descriptions of sensory data (Belardinelli, Palmiero, and Di Matteo 2011). ${ }^{12}$ This proposal returned to many of the unresolved issues from the imageless-thought debates and reflected the ongoing philosophical debates over the role of sense imagery in thought mentioned earlier (Reisberg, Pearson, and Kosslyn 2003).

At the same time, this descriptive/propositional debate facilitated investigation into the neural bases of subjective experiences of mental imagery (Farah 1995; Denis 2012). For example, one of the most prolific avenues of research investigated the neuroanatomical parallels between visual imagery

11. See O. Hobart Mowrer (1977) for a first-person account of the slow process of validating mental imagery as a concept worthy of study within psychology.

12. For overviews of this imagery debate, see Tye 2000; Amiri et al. 2002; Pearson and Kosslyn 2015. 
and visual perception (Intons-Peterson 1992). In addition, investigations of visual imagery contributed to research on working memory, spatial knowledge, and the mental models required for reasoning (Denis 2012). Along the way, visual imagery became the "paradigmatic 'example' of a more general ability to generate and process internal objects regardless of the sensory modality" (Belardinelli and Di Matteo 2002, p. 204). As such, when the concept of mental imagery was used to investigate other modalities of SLMP it was typically framed by research on visual imagery (e.g., Halpern 1988; Stillman and Kemp 1993).

By the end of the twentieth century the descriptive/propositional debate was leaning towards recognizing that at least some mental representations involve SLMP (Behrmann 2000). Indeed, in some cases experiences of mental imagery were once again being positioned as essential for a range of neurocognitive functions (e.g., Mellet et al. 1998). Along the way, the concept of mental imagery came to be used for investigating the roles of ordinary SLMP in a range of healthy neurocognitive functions, from memory tasks to problem solving (Behrmann 2000; Denis 2012).

Whether theorized as essential or merely ordinary elements of cognition, the concept of mental imagery had stabilized for use in investigating a range of neurocognitive function and was able to be used without definition or description (e.g., D'Esposito et al. 1997; Halpern and Zatorre 1999). It is this use of the concept of mental imagery that continues within individual neuroimaging experiments. As ever, ordinary SLMP are characterized, both explicitly and implicitly, as voluntary copies of sensory information that can, if carefully controlled, contribute to various cognitive tasks (e.g., Diekhof et al. 2011; Zvyagintsev et al. 2013). Therefore, while the typical characteristics of mental imagery represent a narrow range of ordinary experiences of SLMP, they have become routine. Carrying along mediator views of ordinary SLMP as necessary for memory and imagination, these characteristics helped to revive the concept of mental imagery for use in neuroimaging experiments, individuating instances of a sub-set of ordinary SLMP for investigating healthy neurocognitive processes.

\section{Hallucinations and the Investigation of Neurocognitive Dysfunction}

In neuroimaging experiments that use the concept of hallucinations, the focus is on investigating neurocognitive dysfunction. In this context, and more broadly, definitions of hallucinations pivot around the notion of a compelling sense of perception occurring despite the absence of relevant sensory stimulation (Blom 2010; Shine et al. 2011; Jardri and Sommer 2013). An example of SLMP with a compelling sense of perception is provided by Alvin Goldstein's report of hearing his "children's individual voice qualities and intonations" despite knowing his children were a 
thousand miles away (Goldstein 1976, pp. 424-5). For Goldstein, this was a hallucination because he was convinced, during the experience, that the voices he heard came "unmistakably... from the air vents on the door" (Goldstein 1976, pp. 424-5).

This compelling sense of perception has been described as "capturing the essence of a hallucinatory experience" (André Aleman and Larøi 2008, p. 15). Nonetheless, consensus as to the precise definition of hallucinations remains elusive (Mast 2005; Larøi et al. 2012). Attempts to explain this essence have generated additional stipulations as to what characterizes pathological hallucinations. In the process, a number of more restrictive definitions have included or excluded specific SLMP "depending on the presence or absence of given characteristics" (Stephane 2013, pp. 86-7). Of these, the commonly emphasized characteristics specify that hallucinations are abnormally vivid, spontaneous/involuntary, obstinate/ uncontrolled, externally located, misattributed to an external source, and readily confused with perception (Barnes et al. 2003; David 2004; Mast 2005; Aleman and Larøi 2008). Regardless of which of these characteristics are emphasized, the consensus is that hallucinations are symptomatic of psychiatric disorders (of one form or another).

As mentioned earlier, the typical characteristics associated with a concept help to stabilize the uses of that concept for individuating instances of a type of phenomena for further investigation. ${ }^{13}$ Focusing on this process, the following historical sketch will outline how the typical characterization of hallucinations helped stabilize this concept for use in individuating pathologized experiences of SLMP for further investigation.

The use of hallucinations as a concept for investigating SLMP as a symptom of multiple diseases emerged within the nineteenth century (Berrios 1996; Aleman and Larøi 2008). An influential definition of hallucinations in the development of this concept was proposed in 1817 by Jean-Etienne Esquirol (Boismont 1860; Peyroux and Franck 2013). This definition proposed that hallucinations are "supposed sensations" that occur independently of the senses and arise from an over-excitation of normal brain function (Esquirol [1838] 1987, p. 109). While rejecting alternative uses of the term hallucination-including for illusions or damage to peripheral sensory nerves-Esquirol ([1838] 1987, p. 93) included "all varieties of delirium which suppose the presence of an object proper to excite one of the senses, although these object may be beyond their reach."

Esquirol proposed a common explanation for hallucinations regardless of whether the SLMP are "seen," "heard," or otherwise "felt." In each

13. See Feest 2010; Bloch 2012a. 
modality, the compelling sense of perception was attributed to unusually high levels of vividness, frequency, persistence, and uncontrollability of SLMP (Esquirol [1838] 1987; Peyroux and Franck 2013). In this view, SLMP have a compelling sense of perception (hallucinations) due to an abnormally high degree of perceptual similarity; this abnormality increases the risk of confusing sense images for perception (a symptom of pathology). This view aligns with philosophical mediator views of SLMP that I mentioned in the previous section; hallucinations were characterized in ways that attributed the pathology of confusing SLMP with perception to an individual failure to recognize or appropriately regulate extreme forms of ordinary SLMP.

Esquirol's proposal was not accepted wholesale. ${ }^{14}$ However, Esquirol was credited with connecting the term hallucinations with the notion that extreme SLMP are caused by an undefined aberration of normal brain function (Boismont 1860). ${ }^{15}$ Indeed, Esquirol's definition of hallucinations is still considered to form the foundation for investigating how neuroanatomical dysfunction relates to those SLMP with a sense of external perception (Aleman and Larøi 2008; G. E. Berrios and Marková 2012).

Within the 1840s continental discourse, Esquirol's characterization of hallucinations was taken up and developed by other psychiatrists and spread into the discourse of English-speaking practitioners (Blount 1857). As it spread, the proposal that hallucinations stem from over-excited imagery prompted debates over which characteristics - abnormal vividness, frequency, persistence, or lack of control - best explained pathological SLMP. Although productive, the precise characterization of pathological hallucinations was heavily contested (G. E. Berrios and Dening 1996).

The characterization that developed from Esquirol's initial proposal was that, while abnormal, hallucinations only indicate pathology when apparent sensations are especially vivid and persistent and, as such, cannot be recognized as hallucinations for regulation by higher faculties (e.g., Esquirol [1838] 1987; Blount 1857). Specifying further, Alexandre Jacques François Brierre de Boismont regarded abnormal SLMP to be pathological only when a lack of volitional control indicated that physical cause had disrupted reason (Peyroux and Franck 2013). Jules Baillarger took a different approach to modifying Esquirol's account of hallucinations. Although agreeing that hallucinations in different sensory modalities stem from a common

14. The interest in veridical hallucinations provides an example of this resistance, see Le Maléfan and Sommer 2015.

15. For an example of how abnormal SLMP were associated with mental disorder prior to the current concept of hallucinations and the difficulty of studying these histories, see Harris 2013. 
physiological cause, Baillarger separated the sometimes pathological hallucinations of sight, touch, taste, and smell from the exclusively pathological experiences of auditory hallucinations (Lothane 1982; Berrios 1996). For Baillarger, pathological SLMP were seen to stem from a failure of the intellect such that involuntary auditory sensations of memory were confused with reality (Berrios 1996).

In addition to modifications, there were direct challenges to Esquirol's inclusive characterization of hallucinations. For example, Louis-Françisque Lélut and François Leuret argued that the concept of hallucinations should exclusively denote pathological phenomena (Rabkin 1970; Aleman and Larøi 2008). Instead of explaining the confusion of pathological hallucinations with perception as due to over-excited imagery, this proposal shifted focus onto identifying the cause of individual failures in rational judgement about uniquely abnormal SLMP. This challenge led to the question of "whether hallucinations are a pathological and morbid symptom or only an exaggeration of a normal phenomenon" (Blandford 1874, p. 515).

Despite these debates, the question of which characteristics reliably distinguish pathological SLMP from other types of SLMP remained unresolved. Regardless of the theoretical view proposed, the combinations of characteristics offered for explaining pathological hallucinations continued to distinguish these SLMP by their abnormal degrees of perceptual similarity (external location, high vividness) and/or their inadequate regulation (lack of insight or volitional control) (Aleman and Larøi 2008). Although different characteristics were emphasized, each carried associations from the philosophical mediator-views: the more persistent or vivid the SLMP the more difficult it would be to control, while an inability to regulate SLMP was, in turn, associated with an individual's failure of reasoned judgement, a physical dysfunction, or both.

As part of these debates, new categories of abnormal SLMP were suggested to describe those SLMP that did not share the full set of characteristics associated with either ordinary mental imagery or those pathological hallucinations experienced as part of insanity (Berrios and Dening 1996). For example, in the 1880s Victor Kandinsky described "hallucinationlike" experiences-intermediate phenomena that were experienced with the vividness and involuntary character of true hallucinations yet without the compelling belief in the external reality of the supposed perception (Berrios and Dening 1996). For each new proposal, various combinations of the same characteristics mentioned earlier were once again offered to explain how some abnormal SLMP were confused with actual perception while others were not. However, empirical techniques to test these various proposals were inadequate and the debates ended inconclusively (Berrios 1996). As such, hallucinations continued to denote both a 
special case of disease symptomology and the dysfunctional extreme of ordinary SLMP.

In the 1870s and 1880s the neurological mechanism for hallucinations suggested by August Tamburini provided the first causal explanation for pathological SLMP accepted by the majority of late nineteenth century psychiatrists (Berrios 1996). The mechanism Tamburini suggested was that the cause of "inner sensations being confused for real perceptions" was the propagation of morbid internal sensations to all parts of the sensory system (Tamburini [1881] 1990, p. 156). This proposal rejected the existing neurological theory that hallucinations stem from an irritation of peripheral sensory organs (Tamburini [1881] 1990). Instead of peripheral irritation, hallucinatory experiences were attributed to an over-excitation within the cortical areas that then spread throughout the entire sensory system. With this attribution, Tamburini's proposal connected Esquirol's psychiatric concept of hallucinations as a dysfunction of ordinary brain function with a neurological mechanism. However, while agreeing that hallucinations of all modalities share a common cause, Tamburini dismissed Esquirol's interest in the subjective experience of these mental phenomena (Berrios 1996). Following this, psychiatrists also began to reject research that involved recording subjective descriptions of hallucinatory experiences across multiple patients (Kales et al. 1990). Instead, research increasingly focused on identifying the discrete biological mechanisms causing these disease symptoms (Murphy 2009).

As psychiatry consolidated as a medical speciality, Tamburini's model provided legitimacy for investigations into the concept of hallucinations as a discrete psychiatric symptom of neurological dysfunction (Berrios 1996). ${ }^{16}$ This combination of psychiatric and neurological approaches laid the groundwork for using the concept of hallucination for investigating any neuroanatomical dysfunctions related to the psychiatric symptom of pathological SLMP. In this context, hallucinations were regarded as a stable natural kind expected to share the same causal mechanism regardless of sensory-modality (Berrios and Marková 2015). Increasingly presented as a natural kind, hallucinations came to be investigated as a discrete type of objectively delineated phenomena (rather than as a descriptive category laboriously delineated from other categories of SLMP). ${ }^{17}$

Within this context, experiments in neurophysiology fostered proposals that hallucinatory experiences might result from disruption of a range of

16. See T.R. Sarbin and J.B. Juhasz (1967) for a discussion of hallucinations within the context of the consolidation of psychiatry as a medical speciality.

17. See Peter Zachar (2014) for more on the ongoing discussion within the philosophy of psychiatry on "natural kinds." 
different normal neurocognitive functions. For example, in 1892 Jules Séglas developed Tamburini's model to suggest two such mechanisms: one a dysfunction in the language production regions of the brain and the other an abnormal activation in regions involved in auditory perception (Peyroux and Franck 2013). This focus on abnormal language and auditory processing (rather than dysfunctional mental imagery) reflects the close relationship between scientific explanations of hallucinatory phenomena and the position of hearing voices as a symptom of the developing concept of schizophrenia (Peyroux and Franck 2013). Indeed, although their role was debated, experiences of hearing voices were conceptualized as auditory-verbal hallucinations (AVHs) - a central diagnostic criteria for schizophrenia (Shergill et al. 2000; Peyroux and Franck 2013). This proposed relationship between hallucinations and schizophrenia was influential in reinforcing the association between particular types of SLMP and pathological neurocognitive disorders (Kales et al. 1990). Although disputed, during the late nineteenth-century this association focused interest on the diagnostic properties of AVHs; overshadowing scientific interest into hallucinatory experiences in other sensory modalities (Collerton et al. 2012).

By the early twentieth century, the dominant approach positioned hallucinations as a form of pathology resulting from a disturbance of normal brain function (David 2004; Berrios and Marková 2012). Consequently, suggestions that hallucinations contained meaningful content and had psychological origins were dismissed as amateurish (Berrios and Marková 2012). Along the way, the view of hallucinations as exaggerated mental imagery began its slow decline (Seitz and Molhom 1947). In its place, the concept of hallucinations became synonymous with an undesirable form of SLMP caused by disruption of an unknown neuroanatomical function. Positioned in this way, the concept of hallucinations were routinely used to investigate dysfunction in a range of neurocognitive processes; with experiments investigating everything from abnormal sensory perception to language processing deficits (Berrios and Marková 2012; Peyroux and Franck 2013).

Despite these increasingly routine experimental uses of the concept of hallucinations, there was still no reliable way of characterizing pathological hallucinations as a discrete type of SLMP. Some of the most influential attempts to remedy this conceptual ambiguity involved proposals for intermediate SLMP that, being neither pathological hallucinations nor ordinary mental images, could account for hallucinatory-like phenomena experienced by otherwise sane people. For example, during the early twentieth century, two distinct forms of pseudo-hallucinations were proposed: one an abnormally vivid form of internal imagery; and the 
other a form of hallucinatory experience with insight (Taylor 1981; Walker 2013).

The first, a version of pseudo-hallucinations popularized by Karl Jaspers, distinguished between three types of SLMP: true hallucinations (those vivid sensory experiences attributed to an external origin); pseudohallucinations (vivid sensory experiences reported as occurring within an inner subjective place); and normal images (effortful and poorly detailed sensory experiences also occurring within an inner subjective space) (Taylor 1981; Peyroux and Franck 2013). Jaspers' approach emphasized that, while a lack of volitional control and strong perceptual resemblance are abnormal (and indicators of pathology), it is the external attribution of an experience of SLMP that is required for classification as true hallucinations (Taylor 1981). The second approach built upon Kurt Goldstein's descriptions of true hallucinations as those believed to be perception to position pseudo-hallucinations as hallucinatory-like experiences that the patient knows are not real (Walker 2013). Whereas Jaspers positioned pseudo-hallucinations as continuous with normal imagery (differentiated by reported location), Goldstein positioned pseudo-hallucinations as continuous with true hallucinations, (differing only by the level of insight) (Walker 2013).

Despite several subsequent attempts to clarify the relationship between differing types of abnormal SLMP, none of the pseudo-hallucination proposals developed into a stable concept (Aleman and Larøi 2008, p. 19). Nonetheless, each attempt provided a flexible category for the numerous hallucinatory experiences that did not fit into a clinician's favored definition of true hallucinations (Berrios and Dening 1996; van der Zwaard and Polak 2001). As with the nineteenth-century debates, the question of how to distinguish between ordinary, abnormal, and pathological SLMP once again remained unresolved.

Reflecting these unresolved questions, a small strand of research even revived interest in the possibility that pathological hallucinations form as the extreme end of a spectrum of ordinary imagery (e.g., Barrett 1993; Saba and Keshavan 1997). However, these studies simply raised more questions. For example, some studies supported Esquirol's view that a predisposition to hallucinate stemmed from an excess of vividness in reports of mental imagery in any sensory modality (Aleman and Vercammen 2013). However, other studies supported the contrary explanation of hallucination pathology as linked to a deficit in a given imagery modality (say auditory imagery) with the predisposition for hallucinations in that modality (such as AVHs) (Al-Issa 1995). Overall, these studies were inconclusive and became less common as techniques moved away from relying on self-reported measurements. 
During the late twentieth-century, there was little interest in the unresolved question of how to differentiate pathological hallucinations from various non-pathological SLMP when investigating dysfunctional neurocognition. In many cases, the concept of hallucinations was being used to investigate neuroanatomical dysfunction without any discussion of the characteristics individuating this conceptualization of pathological SLMP (e.g., Barta et al. 1990). When mentioned at all, typical characteristics of hallucinations were offered in support of an explanation of pathology rather than as a delineation between different forms of SLMP (e.g., Cleghorn et al. 1992). Likewise, when researchers directly assessed a subject's hallucinatory experiences, typical characteristics were presented as self-explanatory indicators of pathological SLMP (e.g., Holroyd et al. 1992). More commonly, experimental researchers using the concept of hallucinations didn't assess SLMP experiences at all. Instead, subject selection often relied upon prior clinical diagnoses (e.g., Dierks et al. 1999). ${ }^{18}$ This practice deferred the difficulty: clinical judgement of pathology continued to rely on questions about the degree of perceptual-similarity (as indicated by external location and vividness of SLMP) and/or an inability to self-regulate (as demonstrated by the lack of volitional control over SLMP and/or lack of insight about SLMP) (Oulis et al. 1995; Frederick and Killeen 1998; APA 2013). ${ }^{19}$

Therefore, whether identified by clinical diagnosis or through a combination of clinical and experimental assessments, experimental subject selection continued to rely on typical hallucinatory characteristics. Even so, these uses of the concept of hallucinations helped to isolate instances of pathological SLMP for investigating various forms of neuroanatomical dysfunction (Copolov et al. 2004; Berrios and Marková 2012). However, rather than investigating hallucinations as over-excited mental imagery, by now it had become far more common to investigate hallucinations as due to dysfunction within a range of alternative neurocognitive processes. For example, experiments during the 1990s investigated the neuroanatomical mechanism responsible for hallucinations in relation to everything from memory and sensory systems, to attention and abstract reasoning (David 1999; Weiss and Heckers 1999). In this way, the concept of hallucinations was increasingly positioned as not only distinct from, but also unrelated to,

18. Challenges for subject selection in neuroimaging research are well-recognized (Thirion et al. 2007). For example, see Kathryn Tabb's (2015) critique of using clinical psychiatric assessments in grouping experimental subjects.

19. A wide range of clinical assessments were equally inconclusive in their attempts to examine various SLMP characteristics as explanations for hallucinations as symptomatic of psychiatric disorders (Frederick and Killeen 1998). 
that of mental imagery. Used in this way, the concept of hallucinations facilitated investigations into the role of SLMP in dysfunctional neurocognition despite the unresolved questions over the ability of these characteristics to distinguish between ordinary and pathological types of SLMP remaining unresolved.

Therefore, despite their failure to reliably characterize a discrete type of pathological SLMP, routinely attributed typical characteristics helped to stabilize the uses of the concept of hallucinations for investigating neurocognitive dysfunction. ${ }^{20}$ Indeed, by the end of the twentieth century, using the concept of hallucinations for pursuing the goal of investigating the role of pathological SLMP in neuroanatomical dysfunction was rarely debated within the context of experimental practice. This goal was approached through various strategies, including investigating whether hallucinatory experiences correlate with abnormal neuroanatomy, aberrant neural activity, or the disruption of ordinary processing of information (Weiss and Heckers 1999). Regardless of the strategy, these neuroimaging experiments routinely presupposed that the concept of hallucinations individuates a discrete type of (pathological) SLMP that involved unique neuroanatomical processes. As such, while sometimes used to test various theories as to the cause of pathological SLMP, the concept of hallucinations was also able to be used in experiments testing theories for the cause of various mental illnesses, as well as in exploratory experiments into the role of pathological SLMP in neuroanatomical dysfunction that were not testing any specific theory at all.

In the intervening years, neuroimaging experiments continue to be reported without clarifying how the SLMP of interest (pathological hallucinations) were singled-out from other forms of SLMP. For example, the concept of hallucinations is routinely used to investigate neuroanatomical dysfunction without any reference to the unresolved ambiguities in distinguishing between pathological hallucinations and various non-pathological SLMP (Linden et al. 2011; Larøi et al. 2012). When mentioned at all, mental imagery is treated as merely one of the many possible neurocognitive functions that, if disrupted, could result in hallucinatory experiences (e.g., Aleman and Vercammen 2013; Dollfus, Alary, and Razafimandimby 2013; Rossell 2013; Varese and Larøi 2013; Woodward and Menon 2013). Nonetheless, isolating instances of hallucinatory experiences still relies on entrenched characterisations of undesirable SLMP as over-excited forms of

20. Note that debate continues within broader discourses, including the anti-psychiatry movement of the 1960s and 1970s, more recent psychiatric-service-user movements, and contributions to critical neuroscience (e.g., Crossley 1998; Escher and Romme 2012; Kirmayer and Gold 2012). 
mental imagery: as SLMP that are projected into external space; lacking volitional control; and readily misattributed/misjudged as actual perception.

Differentiated from ordinary SLMP in this way, the concept of hallucinations stabilized for use in investigating the dysfunctional neuroanatomical mechanisms involved in various mental illnesses. Therefore, although now able to be used without any reference to ordinary SLMP, typical characteristics of pathological SLMP remain relevant for using the concept of hallucinations to investigate a range of neurocognitive dysfunctions. By carrying along mediator views of pathological SLMP as over excited memory and imagination imagery, these characteristics helped to stabilize the concept of hallucinations for use in neuroimaging experiments; individuating instances of those SLMP considered pathological symptoms of neurocognitive dysfunction.

\section{Distinguishing between Mental Imagery and Hallucinations}

Mental imagery and hallucinations are used independently of each other for individuating instances of distinct types of SLMP when investigating functional and dysfunctional neurocognition respectively. This practice simultaneously evokes and obscures the historical connections between these concepts. In examining one of these connections, I have offered two historical sketches. The first focused on how mental imagery stabilized for use in experiments investigating the role of ordinary SLMP in functional neurocognition. The second focused on how the concept of hallucinations stabilized for use in experiments investigating the role of pathological SLMP in dysfunctional neurocognition.

These sketches can now be positioned side-by-side by drawing on recent scholarship examining how the uses of concepts as tools contribute to scientific practice introduced earlier. Doing so highlights that mediator view associations about the interdependence of ordinary and abnormal SLMP played an important role within the conceptual developmental of both mental imagery and hallucinations. In each case, these interdependent associations became entrenched, carried along by the typical characterizations of mental imagery and hallucinations long after classic mediator views of SLMP were discarded. Along the way, the inverse characteristics of ordinary and abnormal SLMP that articulated these interdependent associations helped to stabilize each concept for use as an independent tool for investigating functional and dysfunctional neurocognition respectively.

To highlight this connection, I have described how these inverse mediator view characterizations of ordinary and abnormal SLMP become routinely accepted attributes of the concepts of mental imagery and hallucinations (summarized in Table 1). To recap, hallucinations are generally 
defined as abnormal mental phenomena that are experienced as having a compelling sense of perception. Confusing SLMP with a compelling sense of perception for actual perception is typically attributed to one or more typical hallucinatory characteristics: a high degree of perceptual similarity; projection into perceptual space; and/or the involuntary or uncontrollable nature of the experience. In contrast, definitions of mental imagery emphasize that these ordinary SLMP merely resemble perception, and are considered easy to distinguish from perception due to characteristics such as their low degree of perceptual similarity, internal location, and volitional control.

As emphasized in the preceding historical sketches, the concept of hallucinations began to be characterized in these ways when the available knowledge about SLMP was dominated by philosophical accounts of thought that positioned SLMP as mediating between sensations and abstract reason. Recall that classic mediator-views position experiences where SLMP that have greater persistence or vividness are more difficult to control, with any inability to regulate these SLMP being associated, in turn, with an individual's failure of reasoned judgement, physical dysfunction, or both. In line with this view, the inverse characterization of mental imagery and hallucinations functioned to distinguish between ordinary and pathological SLMP in terms of an individual's ability (or lack thereof) to recognize their SLMP as such and regulate these sensory experiences appropriately.

Within the context of mediator-views of SLMP, characterizing hallucinations as the inverse of mental imagery, and vice versa, made sense. Ordinary SLMP could not be confused for perception if they were to reliably mediate between perception and abstract thought, while abnormal SLMP were characterized as over-excited forms of ordinary SLMP that threatened this mediating role. However, over time the inverse characteristics of mental imagery and hallucinations came to function as routinely accepted attributes of each concept. This recalls Corrinne Bloch's (2012a) account of how characterizing the type of phenomena being conceptualized can function to condense and integrate that knowledge in a way that satisfies the epistemic requirement of differentiating the phenomena of interest from others. From this perspective, the typical characteristics of mental imagery and hallucinations provided causally-fundamental explanations for the type of phenomena of interest within the available knowledge from mediator-views of SLMP. Articulated as such, these characteristics helped to condense and integrate those mediator-views in a way that satisfied the epistemic requirement of differentiating the type of SLMP of interest from other types of SLMP. Then, having helped to stabilize the uses of each concept for investigating ordinary and 
abnormal experiences of SLMP independently of each other, the typical characterizations of mental imagery and hallucinations persisted even after the classic mediator-views of SLMP were abandoned.

As detailed earlier, classic mediator views of SLMP were rejected by scientists using the concepts of mental imagery or hallucinations for investigating neurocognitive function and dysfunction respectively. Briefly, during the late nineteenth and early twentieth centuries hallucinations were increasingly attributed to a range of dysfunctional processes of which mental imagery were demoted to merely one (likely irrelevant) factor. Likewise, the concept of mental imagery was relegated to investigating inconsequential curiosities of childhood thought in the early twentieth century. With these rejections of classic mediator-views of SLMP, the concepts of mental imagery and hallucinations both became detached from their shared philosophical origins. In this way, the explanatory context that the early characterizations of these concepts articulated ceased to explain their relationship.

Despite their limitations, these inverse sets of characteristics retained pragmatic value through their role in explaining the relationship between ordinary, abnormal, and pathological forms of SLMP in relation to the isolated uses of each of these concepts. For example, during the careful justifications for reviving scientific interest in adult experiences of mental imagery during the 1960s, the typical characteristics offered for mental imagery were those thought to ensure that a given experience of SLMP was easily distinguishable from perceptual reality. Justified in this way, the concept of mental imagery came to be used to investigate a uniform type of SLMP assumed to be common to all healthy individuals. Conversely, those characteristics associated with hallucinations came to function as suggested mechanisms for explaining how only some abnormal SLMP have a compelling sense of perceptual reality. However, rather than mechanisms based in an over-excitation of ordinary SLMP, these explanations focused on dysfunctions in language-based reasoning processes and perceptual judgement.

This highlights how the inverse characterizations that emerged from classic mediator-views persisted even after mediator-views of SLMP were jettisoned. Further examples of the preservation of this relationship in latter conceptual rearrangements are provided by the earlier discussions of the rudimentary concepts of eidetic imagery and pseudohallucinations. In each case, these proposals attempted to conceptualize SLMP that shared characteristics with both ordinary mental imagery and pathological hallucinations. As illustrated in Table 2, these attempts - and the diversity of SLMP experiences they highlight — question the boundary between the characteristic experiences of ordinary, abnormal, and pathological SLMP. 
In many ways, the ambiguity of this boundary challenges the reliability of the differentiation of the concepts of mental imagery and hallucinations for use in investigating ordinary and pathological SLMP respectively. However, this challenge went unanswered. Instead, each newly proposed conceptualization of SLMP was intended to explain experiences that were anomalous in relation to either mental imagery or hallucinations (depending on whether the goal was to investigate functional or dysfunctional neurocognitive processes). These explanations therefore drew upon the same series of mediator-view associations relating the controllability of a sense-image with its persistence or vividness and an inability to regulate imagery with a failure of reasoned judgement, a physical dysfunction, or both. In addition, these rudimentary concepts were often proposed by different members of the scientific community, with each emphasizing different characteristics of the principal concept. Considered from a similarity based account of concept taxonomies, each anomaly was able to be minimized in relation to those features considered important within the local context. $^{21}$ The structured delineation between the concepts of mental imagery and hallucinations was therefore preserved through the flexibly applied inverse sets of characteristics: firstly, to delineate between the concepts of mental imagery and hallucinations and, secondly, to distinguish between functional and dysfunctional SLMP in relation to the independent uses of each of these concepts.

This reveals an apparent tension. On the one hand the typical characterizations of mental imagery and hallucinations draw on interdependent associations between ordinary and abnormal SLMP inherited from philosophical mediator-views, associations that have repeatedly failed to differentiate between discrete types of ordinary and pathological SLMP. At the same time, these inverse characterizations helped to stabilize the independent uses of the concepts of mental imagery and hallucinations for investigating mutually exclusive types of ordinary and pathological SLMP respectively. However, this tension can be resolved by recalling that concepts can be used as tools in experiments without needing to pick out eternal natural kinds (Bloch 2012b). Indeed, concepts need not even offer definitive boundaries for reliably referring to a discrete type of phenomena (Kindi 2012). Instead, articulating the typical characteristics associated with a concept merely provides a way to isolate those instances of a type of phenomena in ways that can be further investigated in relation to specific experimental goals. In this way, ascribing typical characteristics to

21. See Hanne Andersen $(2002,2012)$ for more on how minor anomalies are managed within the taxonomies of scientific concepts as used across diverse scientific communities. 
each concept can be seen to have helped stabilize their respective functions for pursuing discrete goals.

Therefore, rather than threaten the contrasting concepts of mental imagery and hallucinations, the ambiguous boundary of diverse characteristics between ordinary, abnormal, and pathological SLMP distanced the uses of each concept from the other. This distance was reinforced by, and sustained, the uses of the concepts of mental imagery and hallucinations as independent tools for investigating distinct goals. Indeed, this distance continues to be maintained through localized proposals of intermediate types of SLMP to conceptualize experiences that fail to align with the typical characteristics of either mental imagery of hallucinations. For example, there continue to be distinctions drawn between pathological and non-pathological hallucinatory experiences on the one hand, and between ordinary mental imagery and intrusive imagery on the other (e.g., Longden, Madill, and Waterman 2012; de Leede-Smith and Barkus 2013; D. G. Pearson et al. 2013). While beyond the present scope, these continued attempts highlight the ongoing difficulties in differentiating between discrete types of SLMP. As with the earlier intermediate types of SLMP (summarized in Table 2), proposals for intrusive imagery and non-pathological hallucinations similarly question the reliability of differentiating discrete types of ordinary and pathological SLMP. Yet, as illustrated in Table 3, the inverse sets of characteristics can be rearranged to simultaneously support three different distinctions: between typical mental imagery and typical hallucinations; between ordinary mental imagery and abnormal imagery; and between pathological and nonpathological hallucinations.

The buffer provided by intermediate types of SLMP both obscures and evokes the entrenched associations that connect how the concepts of mental imagery and hallucinations are each used to investigate SLMP. Borrowing Ingo Brigandt's (2012) terminology, each concept can be considered a dynamic entity composed of three components: the referential component (mental imagery or hallucinations as terms signifying discrete types of SLMP); the inferential role that supports the explanatory link between the term and the phenomenon (the inverse sets of characteristics explain the uses of the concept of mental imagery for investigating ordinary experiences of SLMP and the uses of the concept of hallucinations for investigating pathological experiences of SLMP); and the epistemic goal that sets the standards for the ways in which the mechanisms involved in the phenomena can be investigated (the investigation of functional neurocognitive processes involving ordinary SLMP and the investigation of the dysfunctional neurocognitive processes involving pathological SLMP). 
Structured as mutually exclusive conceptualizations for discrete types of SLMP, each concept came to be used in experiments that investigate specific epistemic goals. As a concept for a type of ordinary SLMP expected to be experienced by all healthy people, mental imagery could be used in neuroimaging experiments seeking to explain various neurocognitive functions. With this goal, the concept of mental imagery is used primarily in experiments that gather data that might explain the mechanisms underlying the role of ordinary SLMP in various neurocognitive functions (e.g., Bird et al. 2010; Zvyagintsev et al. 2013). Conversely, dysfunctional experiences of SLMP are identified as hallucinations based on characteristics suggestive of an inability to appropriately regulate sensations with abstract reason (see: Ratcliff et al. 2011). Once identified, these hallucinatory experiences can then be used in neuroimaging experiments seeking to explain neurocognitive dysfunctions that involve pathological SLMP (e.g., Hoffman et al. 2007; Vercammen et al. 2011). In neuroimaging experiments that use the concept of hallucinations, the goal is to gather data that might identify the mechanisms responsible for types of dysfunctional SLMP implicated in various diseases.

In this way, the concepts of mental imagery and hallucinations each came to operate as tools that individuate discrete types of SLMP by implicit sets of characteristics (suggestive of mediator-view type explanations for either an expected ability or demonstrated inability to appropriately regulate sensations with abstract reason) in ways that are useful for neuroimaging experiments that investigate specific explanatory problems (the neuroanatomical processes contributing to either healthy cognition or the dysfunction symptomatic of mental illness).

\section{Conclusion}

Examining elements within the developmental trajectories of the concepts of mental imagery and hallucinations side-by-side reveals an enduring connection: a set of interdependent associations that each concept inherited from classic mediator views of SLMP. Although these classic views have since been discarded, the interdependent associations remain relevant to their current independent uses as tools in neuroimaging experiments.

To highlight this ongoing relevance, I have outlined how the knowledge of SLMP available in nineteenth century mediator views of SLMP provided an explanation for how a crucial element of thought (ordinary SLMP) could lead to failures in judgment (due to inadequately regulating ordinary SLMP) that were symptomatic of pathology. Although classic mediator views were discarded by the early twentieth century, these explanatory associations were carried along by the typical characterizations 
of each concept. Initially, these typical sets of characteristics were explicitly contrasted to differentiate hallucinations from mental imagery, and vice versa. However, increasingly taken for granted, these characteristics helped each concept to stabilize as an independent tool for investigating ordinary and pathological SLMP respectively. As such, even after investigations using these concepts discarded mediator views of SLMP, the typical characteristics persisted. Carried along by these inverse characterizations, the interdependent mediator view associations about ordinary and abnormal SLMP continued to provide subterranean justifications for the uses of each concept for individuating a discrete type of SLMP for further investigation.

Individuated in this way, the concepts of mental imagery and hallucinations each came to function as tools for investigating neurocognitive function and dysfunction respectively. Even though these goal directed experimental uses stabilized, the ability of a given typical characteristic to differentiate between types of SLMP continued to be questioned in broader discourses. Indeed, there have been multiple unresolved attempts at identifying those characteristics that distinguish between experiences of ordinary, abnormal, and pathological SLMP (see Tables 2 and 3 for examples). However, rather than challenging independent uses of these concepts, these attempts merely reinforced these uses by providing a buffer between them: hallucinations came to be differentiated from various non-pathological hallucinatory-like experiences, and ordinary mental images came to be differentiated from various abnormal variations of mental imagery. Distanced from each other in this way, the concepts of mental imagery and hallucinations can operate as stable conceptual tools, each individuating those instances of a type of SLMP relevant to the goal of investigating functional or dysfunctional neurocognition respectively.

By drawing attention to the connections between the inverse characterizations of functional and dysfunctional SLMP, I have sought to highlight that interdependent associations are entrenched within the uses of the concepts of mental imagery and hallucinations for pursuing independent goals. This supports the recent calls to address the conceptual challenges plaguing neuroimaging practices (Abend 2016; Poldrack and Yarkoni 2016). Indeed, further examination is required to appreciate the implications of these interdependent associations for the current uses of these concepts as tools in neuroimaging experiments. In the meantime, recognizing historical connections between the concepts of mental imagery and hallucinations provides a valuable step in this direction.

To this end, I have highlighted a set of interdependent associations that the concepts of mental imagery and hallucinations each inherited from mediator views of SLMP. In analyzing this connection, I argued that these 
inherited mediator view associations became entrenched, carried along by the typical characterisations of each concept. To support this argument, I drew on scholarships examining how the uses of scientific concepts contribute to experimental practices. In doing so, I have demonstrated that these inverse sets of characteristics helped to integrate nineteenth-century knowledge about SLMP, stabilizing the uses of each concept as independent experimental tools for the specific goals of investigating either functional or dysfunctional neurocognitive processes. As this approach illustrates, there is value in recognizing historical connections between mental imagery and hallucinations for further examinations into the how the uses of each concept contribute to contemporary neuroimaging experiments.

\section{References}

Abend, Gabriel. 2016. "What Are Neural Correlates Neural Correlates Of?" BioSocieties 12: 415-438.

Aleman, André, and Frank Larøi. 2008. Hallucinations the Science of Idiosyncratic Perception. Washington, DC: American Psychological Association. Aleman, Andrè, and Ans Vercammen. 2013. "The 'Bottom-up' and 'Top-down' Components of the Hallucinatory Phenomenon." Pp. 107-122 in The Neuroscience of Hallucinations. Edited by Renaud Jardri, Arnaud Cachia, Pierre Thomas, and Delphine Pins. New York: Springer.

Alexander, H. B. 1904. "Some Observations on Visual Imagery." Psychological Review 11: 319-337.

Al-Issa, I. 1995. "The Illusion of Reality or the Reality of Illusion. Hallucinations and Culture." The British Journal of Psychiatry 166: 368-373.

Allport, Gordon W. 1924. "Eidetic Imagery." British Journal of Psychology. General Section 15: 99-120.

American Psychiatric Association (APA). 2013. "Decision Tree for Hallucinations." Chapter 2, Section 6 in Diagnostic and Statistical Manual of Mental Disorders DSM-5, 5th ed. Arlington, VA: American Psychiatric Association.

Amiri, Hedy, Chad J. Marsolek, Martha E. Arteberry, Catherine CraverLemly, Adam Reeves, Paolo Bartolomeo, Sylvie Chokron, et al. 2002. “Open Peer Commentary on Pylyshyn's 2002 “Mental Imagery: In Search of a Theory." Behavioral and Brain Sciences 25: 182-216.

Andersen, Hanne. 2002. "The Development of Scientific Taxonomies." Pp. 95-111 in Model-Based Reasoning. Edited by Lorenzo Magnani and Nancy J. Nersessian. Boston, MA: Springer US.

Andersen, Hanne. 2012. "Conceptual Development in Interdisciplinary Research." Pp. 271-292 in Scientific Concepts and Investigative Practice. Edited by Uljana Feest and Friedrich Steinle. Berlin: De Gruyter. 
Anderson, Richard C., and Raymond W. Kulhavy. 1972. "Imagery and Prose Learning." Journal of Educational Psychology 63: 242-243.

Andrade, Jackie, Jon May, Catherine Deeprose, Sarah-Jane Baugh, and Giorgio Ganis. 2014. "Assessing Vividness of Mental Imagery: The Plymouth Sensory Imagery Questionnaire.” British Journal of Psychology 105: 547-563.

Angell, James R. 1910. "Methods for the Determination of Mental Imagery." The Psychological Monographs 13: 61-108.

Angell, James R. 1911. "Imageless Thought”. Psychological Review 18: $295-323$.

Armstrong, A. C. Jr. 1894. "The Imagery of American Students." Psychological Review 1: 496-505.

Barnes, J., L. Boubert, J. Harris, A. Lee, and A. S. David. 2003. "Reality Monitoring and Visual Hallucinations in Parkinson's Disease." Neuropsychologia 41: 565-574.

Barrett, Terry R. 1993. "Verbal Hallucinations in Normals-II: SelfReported Imagery Vividness." Personality and Individual Differences 15: 61-67.

Barta, Patrick E., Godfrey D. Pearlson, Richard E. Powers, Stephanie S. Richards, and Larry E. Tune. 1990. "Auditory Hallucinations and Smaller Superior Temporal Gyral Volume in Schizophrenia." American Journal of Psychiatry 147: 1457-1462.

Behrmann, Marlene. 2000. "The Mind's Eye Mapped onto the Brain's Matter." Current Directions in Psychological Science 9: 50-54.

Belardinelli, Marta Olivetti, Massimiliano Palmiero, and Rosalia Di Matteo. 2011. "How FMRI Technology Contributes to the Advancement of Research in Mental Imagery: A Review." Pp. 329-346 in Neuroimaging for Clinicians - Combining Research and Practice. Edited by J. F. P. Peres. London: InTech.

Belardinelli, Marta Olivetti, and Rosalia Di Matteo. 2002. "Is Mental Imagery Prominently Visual?" Behavioral and Brain Sciences 25: 204-205. Berrios, G. E. 1996. The History of Mental Symptoms: Descriptive Psychopathology since the Nineteenth Century. Cambridge, England; New York, NY: Cambridge University Press.

Berrios, G. E. 2013. "Formation and Meaning of Mental Symptoms: History and Epistemology Lecture Presented at the Roman Circle of Psychopathology, Rome, Italy, 16th February 2012." Dialogues in Philosophy, Mental and Neuro Sciences 6: 39-48.

Berrios, G. E. 2014. "History and Epistemology of Psychopathology." Pp. 30-50 in Philosophical Issues in Psychiatry III: The Nature and Sources of Historical Change, edited by Kenneth S. Kendler and Josef Parnas. Oxford: Oxford University Press. 
Berrios, G. E., and T. R. Dening. 1996. "Pseudohallucinations: A Conceptual History." Psychological Medicine 26: 753-763.

Berrios, G. E., and I. S. Marková. 2012. "The Construction of Hallucination: History and Epistemology." Pp. 55-71 in Hallucinations: Research and Practice. Edited by Jan Dirk Blom and Iris E. C. Sommer. New York: Springer.

Berrios, G. E., and I. S. Marková. 2015. "Visual Hallucinations: History and Context of Current Research." Pp. 3-22 in The Neuroscience of Visual Hallucinations, edited by Daniel Collerton. Hoboken, NJ: John Wiley \& Sons.

Betts, George Herbert. 1909. The Distribution and Functions of Mental Imagery. New York: Teachers College, Columbia University.

Bien, Nina, and Alexander T. Sack. 2014. "Dissecting Hemisphere-Specific Contributions to Visual Spatial Imagery Using Parametric Brain Mapping." NeuroImage 94: 231-238.

Bird, Chris M., Corinne Capponi, John A. King, Christian F. Doeller, and Neil Burgess. 2010. "Establishing the Boundaries: The Hippocampal Contribution to Imagining Scenes." The Journal of Neuroscience 30: 11688-11695.

Blandford, George Fielding. 1874. "Auditory Hallucinations." The British Journal of Psychiatry 19: 507-519.

Bloch, Corrinne L. 2012a. "Early Concepts in Investigative Practice - the Case of the Virus." Pp. 191-218 in Scientific Concepts and Investigative Practice. Edited by Uljana Feest and Friedrich Steinle. Berlin: De Gruyter.

Bloch, Corrinne L. 2012b. "Scientific Kinds without Essences." Pp. 233-255 in Properties, Powers, and Structures: Issues in the Metaphysics of Realism. Edited by Alexander Bird, B. D. Ellis, and Howard Sankey. Routledge Studies in Metaphysics, Vol. 5. New York: Routledge.

Blom, Jan Dirk. 2010. A Dictionary of Hallucinations. Springer.

Blount, J. H. 1857. "On the Terms Delusion, Illusion, and Hallucination. Part II." The British Journal of Psychiatry 3: 508-516.

Boon, Mieke. 2012. "Scientific Concepts in the Engineering Sciences: Epistemic Tools for Creating and Intervening with Phenomena." Pp. 219-244 in Scientific Concepts and Investigative Practice. Edited by Uljana Feest and Friedrich Steinle. Berlin Studies in Knowledge Research, Vol. 3. Berlin: De Gruyter.

Bower, Kenneth J. 1984. "Imagery: From Hume to Cognitive Science." Canadian Journal of Philosophy 14: 217-234.

Brann, Eva T. H. 1991. The World of the Imagination: Sum and Substance. Savage, MD: Rowman \& Littlefield.

de Boismont, Alexandre Jacques François Brierre. 1860. On Hallucinations: A History and Explanation of Apparitions, Visions, Dreams, Ecstasy, 
Magnetism, and Somnambulism. Translated by Robert T. Hulme. London: H. Renshaw. Columbus, Ohio: Joseph H. Riley \& Co.

Brigandt, Ingo. 2010. "The Epistemic Goal of a Concept: Accounting for the Rationality of Semantic Change and Variation." Synthese 177: 19-40.

Brigandt, Ingo. 2012. "The Dynamics of Scientific Concepts." Pp. 75-103 in Scientific Concepts and Investigative Practice. Edited by Uljana Feest and Friedrich Steinle. Berlin: De Gruyter.

Camilleri, Kristian. 2015. "The Shaping of Inquiry: Histories of the Exact Sciences after the Practical Turn." Advances in Historical Studies 4: 68-84.

Casey, Edward S. 2000. Imagining: A Phenomenological Study, 2nd ed. Bloomington: Indiana University Press.

Cleghorn, John M., Sheryl Franco, Barbara Szechtman, Ronald D. Kaplan, Henry Szechtman, Gregory M. Brown, Claude Nahmias, and E. Stephen Garnett. 1992. "Toward a Brain Map of Auditory Hallucinations." American Journal of Psychiatry 149: 1062-1069.

Cocking, J. M. 1991. Imagination: A Study in the History of Ideas. London; New York: Routledge.

Collerton, Daniel, Rob Dudley, and Urs Peter Mosimann. 2012. "Visual Hallucinations." Pp. 75-90 in Hallucinations: Research and Practice. Edited by Jan Dirk Blom and Iris E. C. Sommer. New York: Springer. Cooper, L. A. 1995. "Varieties of Visual Representation: How Are We to Analyze the Concept of Mental Image?" Neuropsychologia 33: 1575-1582. Copolov, David L., Andrew Mackinnon, and Tom Trauer. 2004. "Correlates of the Affective Impact of Auditory Hallucinations in Psychotic Disorders." Schizophrenia Bulletin 30: 163-171.

Cronbach, Lee J. 1957. "The Two Disciplines of Scientific Psychology." American Psychologist 12: 671-684.

Crossley, Nick. 1998. "R. D. Laing and the British Anti-Psychiatry Movement: A Socio-historical Analysis." Social Science \& Medicine 47: 877-889.

David, Anthony S. 1999. "Auditory Hallucinations: Phenomenology, Neuropsychology and Neuroimaging Update." Acta Psychiatrica Scandinavica Supplement 99: 95-104.

David, Anthony S. 2004. "The Cognitive Neuropsychiatry of Auditory Verbal Hallucinations: An Overview." Cognitive Neuropsychiatry 9: 107-123.

Denis, Michel. 2012. "Decades of Images: Reminiscences of a Shared Scientific Journey." Pp. 203-254 in From Mental Imagery to Spatial Cognition and Language Essays in Honour of Michel Denis. Edited by Valérie Gyselinck and Francesca Pazzaglia. Hoboken, NJ: Taylor and Francis. 
Denis, Michel, Johannes Engelkamp, and John T. E. Richardson, eds. 1988. Cognitive and Neuropsychological Approaches to Mental Imagery. NATO ASI Series, D: Behavioral and Social Sciences 42. Dordrecht: Springer Netherlands.

Denis, Michel, Emmanuel Mellet, and Stephen M. Kosslyn. 2004. "Neuroimaging of Mental Imagery: An Introduction." Pp. 625-630 in Neuroimaging of Mental Imagery. Edited by Michel Denis, Emmanuel Mellet, and Stephen M. Kosslyn. Hove, UK: Psychology Press.

D’Esposito, M., J. A. Detre, G. K. Aguirre, M. Stallcup, D. C. Alsop, L. J. Tippet, and M. J. Farah. 1997. "A Functional MRI Study of Mental Image Generation”. Neuropsychologia 35: 725-730.

Diekhof, Esther K., Hanne E. Kipshagen, Peter Falkai, Peter Dechent, Jürgen Baudewig, and Oliver Gruber. 2011. "The Power of ImaginationHow Anticipatory Mental Imagery Alters Perceptual Processing of Fearful Facial Expressions." Neurolmage 54: 1703-1714.

Dierks, T., D. E. J. Linden, M. Jandl, E. Formisano, R. Goebel, H. Lanfermann, and W. Singer. 1999. "Activation of Heschl's Gyrus during Auditory Hallucinations.” Neuron 22: 615-621.

Dollfus, Sonia, Mathieu Alary, and Annick Razafimandimby. 2013. "Speech Processing and Auditory Hallucinations." Pp. 123-136 in The Neuroscience of Hallucinations. Edited by Renaud Jardri, Arnaud Cachia, and Pierre Thomas. New York: Springer.

Dumville, Benjamin. 1931. The Fundamentals of Psychology: A Brief Account of the Nature and Development of Mental Processes for the Use of Teachers, 2nd ed. London: University Tutorial Press.

Edgell, B. 1936. Mental Life: An Introduction to Psychology, 4th ed. London: Methuen.

Escher, Sandra, and Marius Romme. 2012. "The Hearing Voices Movement." Pp. 385-393 in Hallucinations: Research and Practice. Edited by Jan Dirk Blom and Iris E. C. Sommer. New York: Springer.

Esquirol, Jean Etienne Dominique. [1838] 1987. Mental Maladies: A Treatise on Insanity. Translated by E. K. Hunt. Birmingham, Ala: Classics of Medicine Library.

Farah, Martha J. 1995. "Current Issues in the Neuropsychology of Image Generation.” Neuropsychologia 33: 1455-1471.

Faw, Bill. 2009. "Conflicting Intuitions May Be Based on Differing Abilities: Evidence from Mental Imaging Research". Journal of Consciousness Studies 16: 45-68.

Feest, Uljana. 2010. "Concepts as Tools in the Experimental Generation of Knowledge in Cognitive Neuropsychology." Spontaneous Generations: A Journal for the History and Philosophy of Science 4: 173-190. 
Feest, Uljana, and Friedrich Steinle. 2012. "Scientific Concepts and Investigative Practice: Introduction." Pp. 1-22 in Scientific Concepts and Investigative Practice. Edited by Uljana Feest and Friedrich Steinle. Berlin Studies in Knowledge Research, Vol. 3. Berlin: De Gruyter.

Ford, Judith M., and Ralph E. Hoffman. 2013. "Functional Brain Imaging of Auditory Hallucinations: From Self-Monitoring Deficits to Co-Opted Neural Resources." Pp. 359-374 in The Neuroscience of Hallucinations. Edited by Renaud Jardri, Arnaud Cachia, Pierre Thomas, and Delphine Pins. New York: Springer.

Frederick, Jane A., and Maureen Reed Killeen. 1998. "Instruments for Assessment of Auditory Hallucinations." Archives of Psychiatric Nursing 12: $255-263$.

French, F. C. 1902. "Mental Imagery of Students: A Summary of the Replies given to Titchener's Questionary by 118 Juniors in Vassar College." Psychological Review 9: 40-56.

Galton, Francis. 1883. Inquiries into Human Faculty and Its Development. London: MacMillan Co.

Goldstein, Alvin G. 1976. "Hallucinatory Experience: A Personal Account." Journal of Abnormal Psychology 85: 423-429.

Golla, Frederick, E. L. Hutton, and William Grey Walter. 1943. "The Objective Study of Mental Imagery: Physiological Concomitants." Journal of Mental Science 89: 216-222.

Gray, Cynthia R., and Kent Gummerman. 1975. "The Enigmatic Eidetic Image: A Critical Examination of Methods, Data, and Theories." Psychological Bulletin 82: 383-407.

Hacking, Ian. 2002. Historical Ontology. Cambridge, Mass: Harvard University Press.

Halpern, Andrea R. 1988. "Mental Scanning in Auditory Imagery for Songs." Journal of Experimental Psychology: Learning, Memory, and Cognition 14: 434-443.

Halpern, Andrea R., and Robert J. Zatorre. 1999. "When That Tune Runs through Your Head: A PET Investigation of Auditory Imagery for Familiar Melodies." Cerebral Cortex 9: 697-704.

Halpern, Andrea R., Robert J. Zatorre, Marc Bouffard, and Jennifer A. Johnson. 2004. "Behavioral and Neural Correlates of Perceived and Imagined Musical Timbre." Neuropsychologia 42: 1281-1292.

Harris, William V. 2013. "Greek and Roman Hallucinations." Pp. 285-306 in Mental Disorders in the Classical World. Edited by William V. Harris. Columbia Studies in the Classical Tradition, Vol. 38. Leiden; Boston: Brill.

Hebb, D. O. 1968. “Concerning Imagery.” Psychological Review 75: 466-477. 
Hoffman, Ralph E., Michelle Hampson, Kun Wu, Adam W. Anderson, John C. Gore, Robert J. Buchanan, R. Todd Constable, Keith A. Hawkins, Neayka Sahay, and John H. Krystal. 2007. "Probing the Pathophysiology of Auditory/Verbal Hallucinations by Combining Functional Magnetic Resonance Imaging and Transcranial Magnetic Stimulation." Cerebral Cortex 17: 2733-2743.

Holroyd, Suzanne, Peter V. Rabins, Daniel Finkelstein, Marie C. Nicholson, Gary A. Chase, and Sally C. Wisnieqski. 1992. "Visual Hallucinations in Patients with Macular Degeneration." American Journal of Psychiatry 149: 1701-1706.

Holt, Robert R. 1964. "Imagery: The Return of the Ostracized." American Psychologist 19: 254-264.

Hubbard, Timothy L. 2013. "Auditory Aspects of Auditory Imagery." Pp. 51-76 in Multisensory Imagery. Edited by Simon Lacey and Rebecca Lawson. New York: Springer.

Hume, David. [1739] 2003. A Treatise of Human Nature. Dover Philosophical Classics. Mineola, NY: Dover Publications.

Intons-Peterson, Margaret Jean. 1992. "Components of Auditory Imagery." Pp. 45-71 in Auditory Imagery. Edited by Daniel Reisberg. Hillsdale, NJ: L. Erlbaum Associates.

Jardri, Renaud, and Iris Sommer. 2013. "Functional Brain Imaging of Hallucinations: Symptom Capture Studies." Pp. 375-392 in The Neuroscience of Hallucinations. Edited by Renaud Jardri, Arnaud Cachia, Pierre Thomas, and Delphine Pins. New York: Springer.

Kales, Anthony, Joyce D. Kales, and Antonio Vela-Bueno. 1990. "Schizophrenia: Historical Perspectives." Pp. 3-23 in Recent Advances in Schizophrenia. International Perspectives Series: Psychiatry, Psychology, and Neuroscience. Edited by Anthony Kales, Costas N. Stefanis, and John Talbott. New York: Springer.

Kind, Amy. 2001. "Putting the Image Back in Imagination." Philosophy and Phenomenological Research 62: 85-109.

Kindi, Vasso. 2012. "Concept as Vessel and Concept as Use." Pp. 23-46 in Scientific Concepts and Investigative Practice. Edited by Uljana Feest and Friedrich Steinle. Berlin: De Gruyter.

Kirmayer, Laurence J., and Ian Gold. 2012. "Re-Socializing Psychiatry: Critical Neuroscience and the Limits of Reductionism." Pp. 307-330 in Critical Neuroscience: A Handbook of the Social and Cultural Contexts of Neuroscience. Edited by Suparna Choudhury and Jan Slaby. Chichester, West Sussex: Wiley-Blackwell.

Kosslyn, Stephen M., M. Behrmann, and M. Jeannerod. 1995. "The Cognitive Neuroscience of Mental Imagery." Neuropsychologia 33: 1335-1344. 
Kosslyn, Stephen M., Giorgio Ganis, and William L. Thompson. 2010. "Multimodal Images in the Brain." Pp. 3-15 in The Neurophysiological Foundations of Mental and Motor Imagery. Edited by Christian Collet and Aymeric Guillot. New York: Oxford University Press.

Kuhlmann, F. 1906. "On the Analysis of the Memory Consciousness: A Study in the Mental Imagery and Memory of Meaningless Visual Forms." Psychological Review 13: 316-348.

Landis, Carney, and Fred A. Mettler. 1964. Varieties of Psychopathological Experience. New York: Holt, Rinehart and Winston.

Langfeld, Herbert Sidney. 1916. "Concerning the Image." Psychological Review 23: 180-189.

Larøi, Frank, Iris E. Sommer, Jan Dirk Blom, Charles Fernyhough, Dominic H. Ffytche, Kenneth Hugdahl, Louise C. Johns, et al., 2012. "The Characteristic Features of Auditory Verbal Hallucinations in Clinical and Nonclinical Groups: State-of-the-Art Overview and Future Directions." Schizophrenia Bulletin 38: 724-733.

Le Maléfan, Pascal, and Andreas Sommer. 2015. "Léon Marillier and the Veridical Hallucination in Late-Nineteenth- and Early-Twentieth-Century French Psychology and Psychopathology." History of Psychiatry 26: 418-432. de Leede-Smith, Saskia, and Emma Barkus. 2013. "A Comprehensive Review of Auditory Verbal Hallucinations: Lifetime Prevalence, Correlates and Mechanisms in Healthy and Clinical Individuals." Frontiers in Human Neuroscience 7: 367.

Linden, David E. J., Katy Thornton, Carissa N. Kuswanto, Stephen J. Johnston, Vincent van de Ven, and Michael C. Jackson. 2011. "The Brain's Voices: Comparing Nonclinical Auditory Hallucinations and Imagery." Cerebral Cortex 21: 330-337.

Logie, Robert H., Cyril R. Pernet, Antimo Buonocore, and Sergio Della Sala. 2011. "Low and High Imagers Activate Networks Differentially in Mental Rotation.” Neuropsychologia 49: 3071-3077.

Longden, Eleanor, Anna Madill, and Mitch G. Waterman. 2012. "Dissociation, Trauma, and the Role of Lived Experience: Toward a New Conceptualization of Voice Hearing." Psychological Bulletin 138: 28-76.

Lothane, Z. 1982. "The Psychopathology of Hallucinations-A Methodological Analysis." The British Journal of Medical Psychology 55: 335-348.

MacKisack, Matthew, Susan Aldworth, Fiona Macpherson, John Onians, Crawford Winlove, and Adam Zeman. 2016. "On Picturing a Candle: The Prehistory of Imagery Science." Perception Science 7: 515.

MacLeod, Miles. 2012. "Rethinking Scientific Concepts for Research Contexts: The Case of the Classical Gene." Pp. 47-74 in Scientific Concepts and Investigative Practice. Edited by Uljana Feest and Friedrich Steinle. Berlin: De Gruyter. 
Mast, Fred W. 2005. "Mental Images: Always Present, Never There." Behavioral and Brain Sciences 28: 769-770.

Mellet, E., L. Petit, B. Mazoyer, M. Denis, and N. Tzourio. 1998. "Reopening the Mental Imagery Debate: Lessons from Functional Anatomy." NeuroImage 8: 129-139.

Mowrer, O. Hobart. 1977. "Mental Imagery: An Indispensable Psychological Concept." Journal of Mental Imagery 1: 303-326.

Murphy, Dominic. 2009. "Psychiatry and the Concept of Disease as Pathology." Pp. 103-117 in Psychiatry as Cognitive Neuroscience: Philosophical Perspectives. International Perspectives in Philosophy and Psychiatry. Edited by Matthew Broome and Lisa Bortolotti. Oxford; New York: Oxford University Press.

Nersessian, Nancy J. 2012. "Modeling Practices in Conceptual Innovation: An Ethnographic Study of a Neural Engineering Research Laboratory." Pp. 245-270 in Scientific Concepts and Investigative Practice. Edited by Uljana Feest and Friedrich Steinle. Berlin: De Gruyter.

Oulis, P. G., V. G. Mavreas, J. M. Mamounas, and C. N. Stefanis. 1995. "Clinical Characteristics of Auditory Hallucinations." Acta Psychiatrica Scandinavica 92: 97-102.

Paivio, Allan. 1969. "Mental Imagery in Associative Learning and Memory.” Psychological Review 76: 241-263.

Paivio, Allan. 1970. "On the Functional Significance of Imagery." Psychological Bulletin 73: 385-392.

Pearson, David G., Catherine Deeprose, Sophie M. A. Wallace-Hadrill, Stephanie Burnett Heyes, and Emily A. Holmes. 2013. "Assessing Mental Imagery in Clinical Psychology: A Review of Imagery Measures and a Guiding Framework." Clinical Psychology Review 33: 1-23.

Pearson, Joel. 2014. "New Directions in Mental-Imagery Research: The Binocular-Rivalry Technique and Decoding FMRI Patterns." Current Directions in Psychological Science 23: 178-183.

Pearson, Joel, and Stephen M. Kosslyn, eds. 2013. Frontiers Research Topics: Mental Imagery. Frontiers Research Topics. Frontiers E-books.

Pearson, Joel, and Stephen M. Kosslyn. 2015. "The Heterogeneity of Mental Representation: Ending the Imagery Debate." Proceedings of the National Academy of Sciences of the United States of America 112: 10089-10092.

Pearson, Joel, and Fred Westbrook. 2015. "Phantom Perception: Voluntary and Involuntary Nonretinal Vision." Trends in Cognitive Sciences 19: 278-284.

Peyroux, Elodie, and Nicolas Franck. 2013. “An Epistemological Approach: History of Concepts and Ideas about Hallucinations in Classical Psychiatry." Pp. 3-20 in The Neuroscience of Hallucinations. 
Edited by Renaud Jardri, Arnaud Cachia, Pierre Thomas, and Delphine Pins. New York: Springer.

Pilgrim, David. 2007. "The Survival of Psychiatric Diagnosis." Social Science \& Medicine 65: 536-547.

Poldrack, Russell A., and Tal Yarkoni. 2016. "From Brain Maps to Cognitive Ontologies: Informatics and the Search for Mental Structure." Annual Review of Psychology 67: 587-612.

Pressley, Michael G. 1976. "Mental Imagery Helps Eight-Year-Olds Remember What They Read." Journal of Educational Psychology 68: 355-359.

Rabkin, R. 1970. "Do You See Things That Aren't There? - Construct Validity of the Concept "Hallucinations."” Pp. 115-124 in Origin and Mechanisms of Hallucinations: Proceedings of the 14th Annual Meeting. New York City, November 14-15, 1969. Edited by Wolfram Keup. New York: Plenum Press.

Ratcliff, Kirk, John Farhall, and Frances Shawyer. 2011. "Auditory Hallucinations: A Review of Assessment Tools." Clinical Psychology \& Psychotherapy 18: 524-534.

Reed, Graham. 1972. The Psychology of Anomalous Experience: A Cognitive Approach. London: Hutchinson.

Reisberg, Daniel, David G. Pearson, and Stephen M. Kosslyn. 2003. "Intuitions and Introspections about Imagery: The Role of Imagery Experience in Shaping an Investigator's Theoretical Views." Applied Cognitive Psychology 17: 147-160.

Rheinberger, Hans-Jörg. 2010. An Epistemology of the Concrete: TwentiethCentury Histories of Life. Experimental Futures: Technological Lives, Scientific Arts, Anthropological Voices. Durham, NC: Duke University Press.

Roeckelein, Jon E. 2004. Imagery in Psychology: A Reference Guide. Westport: Praeger Publishers.

Rossell, Susan L. 2013. "The Role of Memory Retrieval and Emotional Salience in the Emergence of Auditory Hallucinations." Pp. 137-152 in The Neuroscience of Hallucinations. Edited by Renaud Jardri, Arnaud Cachia, Pierre Thomas, and Delphine Pins. New York: Springer.

Saba, P. R., and M. S. Keshavan. 1997. "Musical Hallucinations and Musical Imagery: Prevalence and Phenomenology in Schizophrenic Inpatients." Psychopathology 30: 185-190.

Sarbin, T. R., and J. B. Juhasz. 1967. "The Historical Background of the Concept of Hallucination." Journal of the History of the Behavioral Science 5: 339-358.

Schaffner, Kenneth F., and Kathryn Tabb. 2014. "Varieties of Social Constructionism and the Problem of Progress in Psychiatry." Pp. 85-106 in 
Philosophical Issues in Psychiatry III: The Nature and Sources of Historical Change. Edited by Kenneth S. Kendler and Josef Parnas. Oxford University Press.

Schickore, Jutta. 2002. "(Ab)Using the Past for Present Purposes: Exposing Contextual and Trans-Contextual Features of Error." Perspectives on Science 10: 433-456.

Schilder, Paul. 1933. "Experiments on Imagination, after-Images and Hallucinations." American Journal of Psychiatry 90: 597-611.

Sciortino, Luca. 2016. "On Ian Hacking's Notion of Style of Reasoning." Erkenntnis, 82: 244-264.

Scull, Andrew. 1983. "The Domestication of Madness." Medical History 27: 233-248.

Seitz, P., and H. B. Molhom. 1947. "Relation of Mental Imagery to Hallucinations." Archives of Neurology \& Psychiatry 57: 469-480.

Shergill, S. S., M. J. Brammer, S. R. Williams, R. M. Murray, and P. K. McGuire. 2000. "Mapping Auditory Hallucinations in Schizophrenia Using Functional Magnetic Resonance Imaging." Archives of General Psychiatry 57: 1033-1038.

Shine, James M., Glenda M. Halliday, Sharon L. Naismith, and Simon J. G. Lewis. 2011. "Visual Misperceptions and Hallucinations in Parkinson's Disease: Dysfunction of Attentional Control Networks?" Movement Disorders 26: 2154-2159.

Short, P. L. 1953. "The Objective Study of Mental Imagery." British Journal of Psychology. General Section 44: 38-51.

Steinle, Friedrich. 2010. "Scientific Facts and Empirical Concepts: The Case of Electricity." Pp. 32-43 in Science as Cultural Practice. Edited by Moritz Epple and Claus Zittel. Wissenskultur Und Gesellschaftlicher Wandel, Vol. 24. Berlin: Akademie Verlag.

Steinle, Friedrich. 2012. "Goals and Fates of Concepts: The Case of Magnetic Poles." Pp. 105-126 in Scientific Concepts and Investigative Practice. Edited by Uljana Feest and Friedrich Steinle. Berlin: De Gruyter.

Stephane, Massoud. 2013. "Standardized Assessment of Hallucinations." Pp. 85-104 in The Neuroscience of Hallucinations. Edited by Renaud Jardri, Arnaud Cachia, Pierre Thomas, and Delphine Pins. New York: Springer.

Stillman, Jennifer, and Tiffany Kemp. 1993. "Visual versus Auditory Imagination: Image Qualities, Perceptual Qualities, and Memory." Journal of Mental Imagery 17: 181-194.

Tabb, Kathryn. 2015. "Psychiatric Progress and the Assumption of Diagnostic Discrimination." Philosophy of Science 82: 1047-1058.

Tamburini, August. 1990. "A Theory of Hallucinations." Translated by G. E. Berrios. History of Psychiatry 1: 151-156. 
Taylor, F. Kräupl. 1981. "On Pseudo-Hallucinations." Psychological Medicine 11: 265-271.

Thirion, Bertrand, Philippe Pinel, Sébastien Mériaux, Alexis Roche, Stanislas Dehaene, and Jean-Baptiste Poline. 2007. "Analysis of a Large FMRI Cohort: Statistical and Methodological Issues for Group Analyses." Neurolmage 35: 105-120.

Tiles, Mary. 1984. Bachelard, Science and Objectivity. Modern European Philosophy. Cambridge: Cambridge University Press.

Titchener, Edward Bradford. 1909. "Imagery and Sensationalism." Pp. 3-37 in Lectures on the Experimental Psychology of the Thought-Processes. New York: MacMillan Co.

Tye, Michael. 2000. The Imagery Debate. MIT Press.

Varese, Filippo, and Frank Larøi. 2013. "Missattributions Models (I): Metacognitive Beliefs and Hallucinations." Pp. 153-168 in The Neuroscience of Hallucinations. Edited by Renaud Jardri, Arnaud Cachia, and Pierre Thomas. New York: Springer.

Vercammen, Ans, Henderikus Knegtering, Richard Bruggeman, and André Aleman. 2011. "Subjective Loudness and Reality of Auditory Verbal Hallucinations and Activation of the Inner Speech Processing Network." Schizophrenia Bulletin 37: 1009-1016.

Walker, Chris. 2013. "Form and Content in Jaspers' Psychopathology." Pp. 76-94 in One Century of Karl Jaspers 'General Psychopathology'. Edited by Giovanni Stanghellini and Thomas Fuchs. International Perspectives in Philosophy \& Psychiatry. Oxford: Oxford University Press.

Waller, David, Jeffrey R. Schweitzer, J. Ryan Brunton, and Roger M. Knudson. 2012. "A Century of Imagery Research: Reflections on Cheves Perky's Contribution to Our Understanding of Mental Imagery." The American Journal of Psychology 125: 291-305.

Wang, Jing, Julie A. Conder, David N. Blitzer, and Svetlana V. Shinkareva. 2010. "Neural Representation of Abstract and Concrete Concepts: A Meta-Analysis of Neuroimaging Studies." Human Brain Mapping 31: $1459-1468$.

Weiss, Anthony P., and Stephan Heckers. 1999. "Neuroimaging of Hallucinations: A Review of the Literature." Psychiatry Research: Neuroimaging 92: 61-74.

Woodward, Todd S., and Mahesh Menon. 2013. "Misattribution Models (II): Source Monitoring in Hallucinating Schizophrenia Subjects." Pp. 169-184 in The Neuroscience of Hallucinations. Edited by Renaud Jardri, Arnaud Cachia, and Pierre Thomas. New York: Springer.

Woodworth, R. S. 1915. "A Revision of Imageless Thought." Psychological Review 22: 1-27. 
Zachar, Peter. 2014. "Beyond Natural Kinds: Towards a "Relevant" "Scientific" Taxonomy in Psychiatry." Pp. 75-104 in Classifying Psychopathology: Mental Kinds and Natural Kinds. Edited by Harold Kincaid and Jacqueline A. Sullivan. Philosophical Psychopathology. Cambridge, Massachusetts: The MIT Press.

Zvyagintsev, Mikhail, Benjamin Clemens, Natalya Chechko, Krystyna A. Mathiak, Alexander T. Sack, and Klaus Mathiak. 2013. "Brain Networks Underlying Mental Imagery of Auditory and Visual Information." European Journal of Neuroscience 37: 1421-1434.

van der Zwaard, Roy, and Machiel A. Polak. 2001. "Pseudohallucinations: A Pseudoconcept? A Review of the Validity of the Concept, Related to Associate Symptomatology." Comprehensive Psychiatry 42: 42-50. 